\title{
The making of scientific ethics - lessons from unethical conducts
}

\author{
Kholhring Lalchhandama \\ Department of Zoology/Life Sciences, Pachhunga University College, Aizawl 796001, Mizoram, India
}

\begin{abstract}
With its importance in and influence to our lives, well-being and survival, science has never been more vulnerable to prejudices and scandals as a platform of all sorts of academic misconducts. Lessons are taught by some of the biggest unethical conducts in the recent past which had prompted more stringent ethical guidelines and publication procedures. The case of Yoshitaka Fujii as a scientist with the most number of publications retracted is astonishing. The ability of Yoshihiro Sato to deceive the world leading journals and their referees is astonishing. These cases show that individual or few publications with fabricated data is impervious to detection, but when a series of such faked results is available, it cannot dodge the function of reviewing eventually. The story of Hwang Woo-Suk will forever remain a quintessential pitfall of scientific corruption. The way the purported creation of human stem cell deceived one of the leading journals in the world will be a scientific monument. What could more exemplify breaching ethical standards in human experimentation at the highest level than by He Jiankui's creation of gene-edited babies? These are the chronicles in the science hall of shame.
\end{abstract}

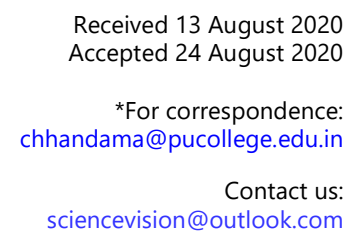

Key words: Ethics, fabrication, forgery, misconduct, fraud.

\section{The Grandmaster of Salami Slicing}

Yoshitaka Fujii (Figure 1) is a Japanese medical researcher in anaesthesiology who had worked at Tokyo Medical and Dental University, the University of Tsukuba, and Toho University. His research focussed on clinical trials of medications in the treatments of nausea and vomiting that often occurs after surgery. Most of his papers were on randomised, double-blind, placebo-controlled trials, regarded as the "gold standard" in medical practice for deciding the usefulness of medicines. A highly productive researcher, he published around 250 articles between 1991 and 2011 with an average of 12 publications per year. But a systematic reassessment of his prolific career revealed events of unbecoming practice. He has been discredited as a "world record" holder for data falsification and fabrication, ${ }^{1}$ having no less than 183 publications retracted from different journals. ${ }^{2}$

Fujii's earliest paper to be retracted was "Contractility of fatigued diaphragm is improved by dobutamine" published in the Canadian Journal of Anaesthesia while he was at the Tokyo Medical and Dental University School of Medicine. ${ }^{3}$ The paper published in May 1993 indicates that his profuse but profane publications began from that moment. The paper was retracted in November 2012, with the stated reason:

Many variables reported in the studies are exceedingly unlikely. The author's institution is not 
able to attest the integrity of the study and/or the data conducted under its auspices. ${ }^{4}$

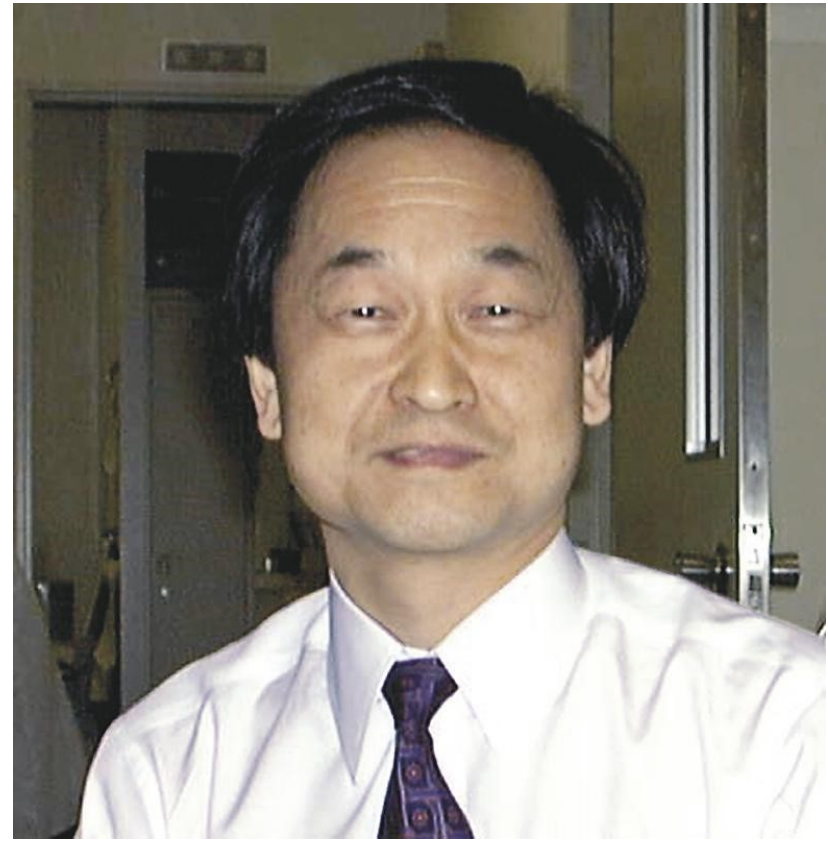

Figure 1 | Yoshitaka Fujii - The Great Pretender, as The Chronicles named him.

How was the misconduct discovered? It was not a simple spot-the-odd-one-out revelation. The initial suspicion arose when three German anaesthesiologists Peter Kranke, Christian Apfel, and Norbert Roewer noticed abnormally good results in Fujii's study of ramosetron and granisetron in preventing postoperative nausea and vomiting which was published in Anesthesia \& Analgesia in 1999. ${ }^{5}$ The data were just too nice. They further analysed Fujii's 47 papers related to the clinical trials of granisetron. The good data was not a pure coincidence. In their letter to the editor of Anesthesia \& Analgesia in April 2000, the German physicians wrote:

We read with interest the recent article of Fujii et al. $\left.{ }^{5}\right]$ about granisetron in the prevention of postoperative nausea and vomiting (PONV). With increasing amazement, we noticed that the results reported by Fujii et al. are incredibly nice and we became skeptical when we realized that side effects were almost always identical in all groups... Thus, [after analysing Fujii's 47 papers] we have to reject the null hypothesis that the frequency of identical results simply occurred because of the assumption that the incidence of headache is not affected by the intervention, and we have to conclude that there must be an underlying influence causing such incredibly nice data reported by Fujii et al. ${ }^{6}$

Fujii quickly rebutted his opponents and clarified to the same journal by ardently objecting to the criticisms of his work, insisting that the "incidence of headache seems to be identical, but it was true. How much evidence is required to provide adequate proof about antiemetics? ${ }^{7}$ But his opponents were determined. Apfel wrote to the U.S. Food and Drug Administration, the Japanese Pharmaceuticals and Medical Devices Agency, and the Japanese Society of Anesthesiologists alerting them to the apparent unreliability of Fujii's results, but in vain. ${ }^{8}$ There was no action taken against Fujii's research but rather journals continued to accept new papers submitted by Fujii. Anesthesia \& Analgesia alone published 11 papers of Fujii after the initial allegation. The editors of Anesthesia \& Analgesia turned deaf ears to the allegations against Fujii until about 2010, when its editor and the editors of several other journals began a coordinated investigation into the integrity of Fujii's scientific publications following new concerns voiced by the editor-in-chief Steven L. Shafer. In March 2012, the editor of Anesthesia \& Analgesia acknowledged that the journal's response to the allegations made in 2000 had been "inadequate."

By that time, the Toho University was making an investigation on Fujii, who was then an Associate Professor, following a report a year before. In August 2011 a complaint alleging false data in nine papers of Fujii was lodged. The Toho University found 13 papers published between 2006 and 2011 not approved by the Institutional Research Board and were retracted from various journals. On 7 March, Toho University reported finding that although nine of Fujii's publications were about clinical studies described as having been conducted at Ushiku Aiwa General Hospital, the hospital's ethics committee had given Fujii approval for only one study. Following this discovery, eight of the nine papers were retracted for failure to follow established ethical standards for clinical research. The inquiry committee resolved thus:

After the investigation, the committee asked Dr. Yoshitaka Fujii and his co-author, Dr. Michiyo Itakura, to explain the whole circumstances. Dr. Fujii admitted that the clinical studies were done without any ethics committee's approval. Dr. Itakura, however, was not involved in this misconduct. Dr. Yoshitaka Fujii sent letters of retraction to the affected journals. We organized a disciplinary committee and decided that a disciplinary dismissal was appropriate for Dr. Fujii, effective from February $29,2012 .^{10}$

In February 2012, after initial investigations into allegations of scientific misconduct, he was dismissed from his position as associate professor of anaesthesiology in the Toho University Faculty of Medicine. Yet, there was no concern of possible fraud. John Carlisle (Figure 2), an English anaesthetists at National Health Service in Torquay had noted that in the late 2000s that Fujii's reports 
were too nice to be factual. Fujii, who then worked at Toho University, reported the effects of different medicines for preventing vomiting and nausea in patients after surgery. To Carlisle, the data looked too ideal. ${ }^{11}$ After analysing all available Fujii's publication from 1991 to July 2011, involving 168 randomised control trials, he reported to the journal Anaesthesia in 8 March 2012 with the conclusion:

In conclusion, I have shown that the distributions of continuous and categorical variables reported in Fujii's papers, both human and animal, are extremely unlikely to have arisen by chance and if so, in many cases with likelihoods that are infinitesimally small. Whether the raw data from any of these studies can be analysed, and whether this might provide an innocent explanation of such results, is beyond the scope of this paper. Until such a time that these results can be explained, it is essential that all Fujii et al.'s data are excluded from meta-analyses or reviews of the relevant fields. ${ }^{12}$

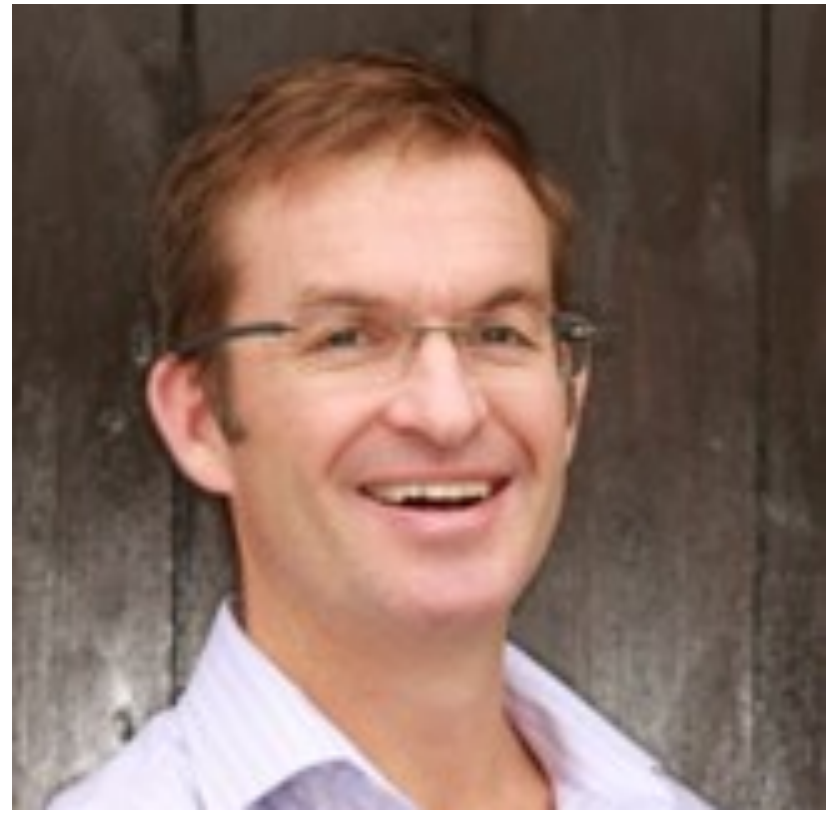

Figure 2 | John Carlisle - - The medical Sherlock Holmes in Fujii's case.

From that point onward, suspicion of fraud was looming largely in the air. On 9 April, the editors of 23 scientific journals made a public request for an investigation of Fujii's research concerning the seven Japanese institutions named as affiliations in his published papers. A committee of the Japanese Society of Anesthesiologists, headed by Koji Sumikawa of Nagasaki University, undertook an examination of 212 of the 249 papers credited to Fujii. The committee interviewed Fujii's listed coauthors and other people who had been involved with Fujii's research. Committee members also attempted to obtain and review laboratory notebooks, patient records, and other raw data from his studies. On 29 June 2012, the committee reported findings that a total of 172 papers contained concocted data. Of these, 126 papers were validated to have been "totally fabricated". Three were found to be genuine, while 37 could not be resolved. The report stated: "It is as if someone sat at a desk and wrote a novel about a research idea." The committee further remarked the malpractice as: "It is as if someone sat at a desk and wrote a novel about a research idea." ${ }^{13}$

The investigators observed that Fujii seemed to have been deliberately ambiguous about details such as the dates of the studies and the names of the institutions where they were conducted, apparently to reduce the possibility that his fraud would be detected. Also, by listing co-authors from institutions other than his current employer, he conveyed the impression that the papers described studies done at multiple hospitals. ${ }^{14}$ Several scientists listed as co-authors were not aware that Fujii had included their names on his papers; two named co-authors said that their signatures had been forged on a cover letter submitting the paper to the journal. ${ }^{1514}$ Retraction Watch suggested that the supposed co-authors might not have been aware that their names had been misused because the papers had received few citations. ${ }^{15}$

The only suspicious co-author was Hidenori Toyooka. Investigators found Toyooka would have been aware of the deception. ${ }^{14} \mathrm{He}$ was Fujii's supervosir at the University of Tsukuba, and later worked with him at Tokyo Medical and Dental University. As such his name was in dozens of Fujii's papers. The investigation reported that he was "was not involved in fabrication but bears significant responsibility. ${ }^{\prime 13}$

\section{Bones of Contention}

Yoshihiro Sato (Figure 3) was a Japanese physician, a neurologist who had worked at Kurume University Medical Center in Kurume, and later at the Mitate Hospital in Tagawa. His speciality on bone research was well known from his copious publications involving several dozens of clinical trials. When review research was done related to his works, the immense number of his data became questioned as they were practically impossible to produce in short spans of time in between his publications. A concentrated analysis of his works revealed that he had plagiarised, fabricated data and forged authorship in his papers published between 1993 and 2013 - a publication fraud on an epic scale. Investigations and reanalyses resulted in retraction of more than 60 papers all bearing his name in different journals of international repute. As the scale of his misconduct was brought to light, Science reported it as an "epic scientific fraud", ${ }^{16}$ while Nature referred to it as "one of 
science's biggest frauds." ${ }^{17}$ [I chose Sato's story over that of Joachim Boldt, a German anaesthesiologist, who holds a record of second highest number of retraction with 100 papers retracted, because of its systematic investigation and tragic end.]

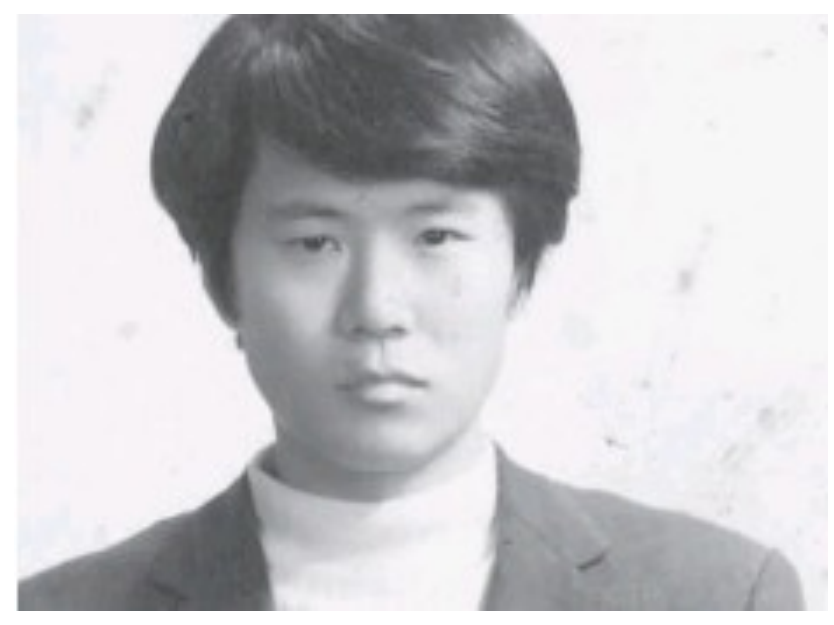

Figure 3 | Yoshihiro Sato - The kamakize fraudster.

The University of Auckland, New Zealand, medical researchers Mark J. Bolland, Alison Avenell (now Professor and Clinical Chair in Health Services Research, the University of Aberdeen, UK), Greg D. Gamble, Andrew Grey made the formal exposé in the December 2016 issue of Neurology, the journal which had already retracted three of Sato's papers. ${ }^{18}$ Since 2006, Avenell had come across Sato's works in clinical trials and was astonished at the quantity of clinical trials conducted by one person and the good results which were too good to be true. In her first brush with Sato's paper she noticed how Sato showed that vitamin $D$ reduces the risk of bone fractures with very good results. Two papers immediately caught his attention. One paper involved stroke victims, while the other Parkinson's disease patients. What was peculiar was that in both the studies the control and study groups had the exact same mean body mass index. Reading other papers of Sato, similar anomalies were clearly evident everywhere. They were not at reliable to include in her work, so she kept aside the papers.

A year earlier, the University of Cambridge researchers had pointed out to Neurology that Sato's paper on the effect of risedronate on hip fractures in women had a near impossible data. Sato, as it was presented, recruited 374 patients in just four months. $^{19}$ In 2007, concerns were raised to the Archives of Internal Medicine in which Sato had recently published two papers. One study involved 280 patients recruited in two months, and the other had 500 patients in three months. ${ }^{20}$ Inquiry was probed by the journal upon which Sato defended his study, replying publicly in the same journal, he wrote,
Although it was described that the study was done in a single hospital, I requested my physician colleagues of other nearby hospitals to participate in the 2 studies... I apologize for confusing the readers of the ARCHIVES by not providing the numbers of patients in other hospitals involved in the studies. The authors did not describe this fact, the reason being that these hospitals were reluctant to have their names in the article. ${ }^{21}$

Sato appeared to come clean in this contention and his explanation was accepted. But then a dark fate was already sealing his future. Teaming up with the Auckland specialists in clinical trial since 2008, Avenell had not forgotten Sato's papers as they again crept up when she performed research analyses. When she brought Sato's case up in 2012, Bolland was astonished and quick to exclaim, "There is nothing that I can think of that produces a $70 \%$ to $80 \%$ reduction in hip fractures, yet Sato was able to do it consistently in all his trials." When they performed statistical analyses on 33 clinical trials reported by Sato, they found that the randomized groups were incredibly similar. "There was just one plausible explanation," Bolland said, "Sato had fabricated data for both groups and had made them more similar than they would ever be in real life." ${ }^{16}$

Avenell and Auckland researchers' report to Neurology had interesting reactions and consequences. Their manuscript titled "Systematic review and statistical analysis of the integrity of 33 randomized controlled trials" was submitted on 4 December $2015{ }^{18}$ but it was not decided for acceptance in the usual journal timeline, as Robert $A$. Gross, the Editor-in-Chief, later reported: "[The] manuscript has a different focus as it presents a statistical analysis that demonstrates probable scientific misconduct (fraud) on a large scale. It is also unique in that its analysis uses complicated methods that may be beyond what most readers are willing to tackle." ${ }^{22}$ The delay was aptly justified. It took three statisticians to evaluate the findings, and as the results were convincing, the journal asked explanation from Sato. In response, Sato admitted the papers were fraudulent and that his co-authors were not involved in the fraud. The three papers in Neurology were retracted on 11 July 2016. What followed was acceptance of Bolland et al.'s paper on 24 August and its publication on 9 November 2016, and the finding was:

There were multiple examples of inconsistencies [in Soto's 33 papers] between and within trials, errors in reported data, misleading text, duplicated data and text, and uncertainties about ethical oversight. ${ }^{18}$

As Neurology announced retractions, other journals such as JAMA Internal Medicine, and Journal of Bone and Mineral Research followed suit and 10 of Sato's papers were retracted by the end of 2016. In March 2017, Avenell received a news from Neurology editor that Sato was dead. Sato had died 
in January $2017 .^{23}$ The cause of death was not disclosed immediately to which Avenell later remarked, "We have no indication that he committed suicide, but it concerns us." A suicide note was later revealed by Satos' lawyer that sated "I decided to commit suicide." 16

\section{The Pride of Korea, a Disgrace to Science}

Hwang Woo-Suk (Figure 4) was not called the "Pride of Korea"24 for no reason. A South Korean veterinarian at the Seoul National University specialised in stem cell research, he was the first to create a cow by in vitro fertilisation (IVF) in 1993, and then the first cloned cow, named Yeongrong-i, in February 1999. He was fondly embraced as a "national hero." ${ }^{25}$ As if simply cloning was not much use in human welfare, he cloned the first mad cow disease-resistant cows in 2003. ${ }^{26}$ On 12 February 2004, Hwang and his team publicly announced that they had successfully done the first human cloning by creating an embryonic stem cell with the somatic cell nuclear transfer method, whereby a nucleus of somatic cell is transferred into oocyte that is removed of its nucleus to make a viable embryo. The paper was published in the 12 March 2002 issue of Science. ${ }^{27}$ Praises were bound to come, as Time magazine rated him and his friend Shin Yong Moon at 84 in its list of the most influential people in the world, The 2004 TIME $100 .{ }^{28}$

It was not a mere compliment when he announced the first clone of a dog, Snuppy, an Afghan hound, in 2005. When his team published the cloning result in the 4 August issue of Nature, ${ }^{29}$ it

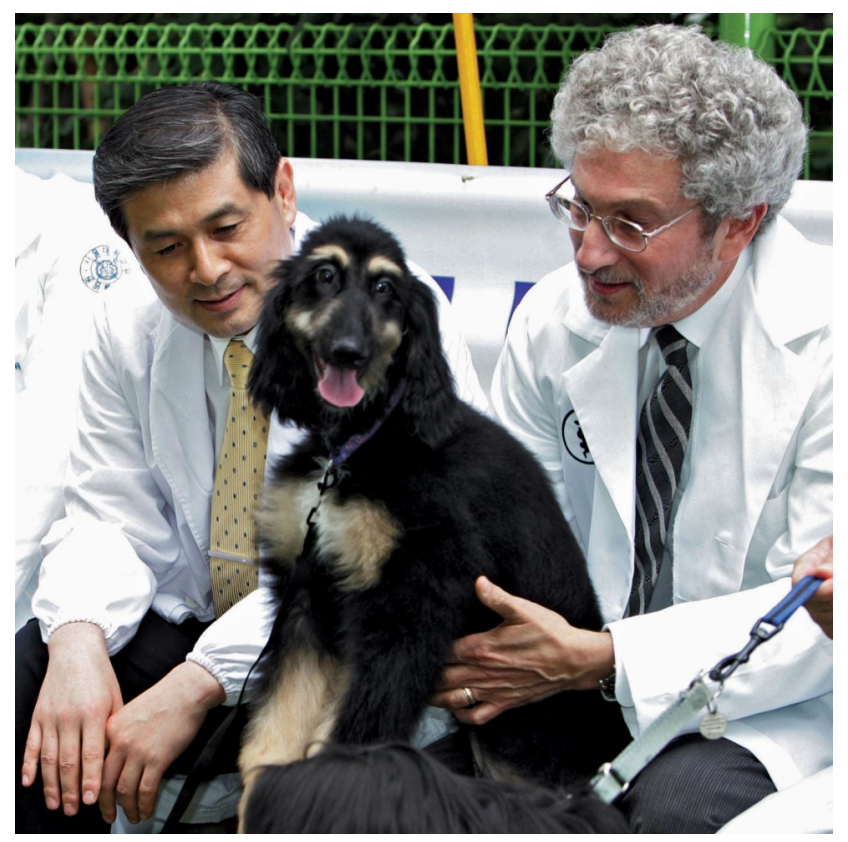

Figure 4 | Hwang Woo-Suk (left), Snuppy (centre) and Gerald Schatten during their happy times. could not be helped but it was media and scientific sensation. $^{3031}$ Snuppy was named the Times's "Invention of the Year." 32 But everything about his pride and prestige crumbled to the ground of humility, as Nature documents: "The work shot him to international fame, and then infamy." 25

Hwang's works were already under sceptical view when he made news of cloning of cows since he had no scientific publications to support his achievements. It was from this shortfall that he published his cloning of human cell and dog in the most reputed journals, Science and Nature, respectively. In Science, Hwang's team reported that:

[We] report the derivation of a pluripotent embryonic stem (ES) cell line (SCNT-hES-1) from a cloned human blastocyst. The SCNT-hES-1 cells displayed typical ES cell morphology and cell surface markers and were capable of differentiating into embryoid bodies in vitro and of forming teratomas in vivo containing cell derivatives from all three embryonic germ layers in severe combined immunodeficient mice. After continuous proliferation for more than 70 passages, SCNT-hES1 cells maintained normal karyotypes and were genetically identical to the somatic nuclear donor cells. $^{27}$

It was a milestone in biology - the creation of human cells by cloning, a new era of therapeutic cloning. But the immediate question was, where do the human egg cell came from? It was not declared explicitly by Hwang. As soon as the news broke, Korean citizens'-rights activists and bioethicists demanded to see the ethical documents relating to the recruitment of women volunteers. From the Science paper all that was evident was that 242 eggs were obtained from 16 volunteers to create a single line of embryonic stem cells. To enhance ovulation, the volunteers were given hormone injections so that they were able to produce 12 to 20 eggs per menstrual cycle instead of one. It could cause a serious ethical issue. When asked, Hwang did give some credible explanations that the volunteers were recruited properly. But there was one inconsistency. Ja Min Koo, one of the co-authors and a Ph.D. scholars had confided to Nature reporter that she and her friend (later identified as Eul Soon Park, who developed the nucleus transfer technique ${ }^{25}$ ) in the lab had donated their eggs. But Hwang denied their involvement as donors, and refused to disclose the consent documents of the volunteers. Something was clearly fishy. David Cyranoski reported this ethical conundrum in 6 May 2004 issue of Nature. $^{33}$ It was a disappointment of huge implication as no further investigation or action was taken.

To spike up his glory, Hwang and his team published another human cell cloning in the June 17 2005 issue of Science. The paper reports the successful production of 11 human embryonic stem cells using 185 eggs, and more importantly, the stem 
cells were patient specific, meaning that they were immunologically compatible to the donor, as the paper reported:

NT-hESCs [nuclear transfer-human embryonic stem cells] were pluripotent, chromosomally normal, and matched the NT patient's DNA. The major histocompatibility complex identity of each NThESC when compared to the patient's own showed immunological compatibility, which is important for eventual transplantation. ${ }^{34}$

Immunological compatibility further implies that it was going to be a milestone in transplantation, cell could be made to match a person's somatic cells so that there will not be undesirable immune reactions. As would be obvious, Ja Min Ko was not there in the team. Thereafter, a series of revelations was unrolling one after another. In June 2005, a former member of Hwang's laboratory tipped off the Munhwa Broadcasting Company ( $\mathrm{MBC}$ ) producers regarding the fraudulent nature of the 2005 Science paper. Then PD Notebook (PD Su-cheop), an investigative journalism program of $\mathrm{MBC}$, received stem-cell line number 2 , one of 11 cells supposedly tailored to a patient, for testing. There was also a third informer who corroborated to both the assertions. The MBC investigators got their teeth into the case. ${ }^{25}$

By November 2005, testimonies began to surface. Sung II Roh, a fertility specialist at MizMedi Hospital in Seoul and co-author of the 2005 paper, was interrogated by the police on 8 November on the source of the eggs. ${ }^{35}$ The Korean press spread the news that Roh had illegally traded eggs. ${ }^{36}$ In response, Gerald Schatten from the University of Pittsburgh who was Hwang's collaborator, backed up Hwang's research by writing on 10 November to the Science editors that there were no paid donors. A day after, telling Science, he realised that there were indeed consent issues in the 2004 paper. He wisely decided to wash his hands off of Hwang's affair and announced on 12 November that he formally cut all ties with Hwang as he suspected inappropriate use of human eggs. ${ }^{37}$ He accused Hwang of deliberate misinformation as to how the oocytes were procured. Hwang and his team equivocally defended that the allegation was false. ${ }^{38}$

Ten days later on 21 November, Roh confessed that he had indeed paid at least 20 women $\$ 1430$ each for eggs they used in the 2004 study. The eggs were collected in 2002, as he said, when there was no bioethical law in Korea, but Hwang was not informed of this. ${ }^{39}$ Bioethics law was enforced on 1 January 2005 only, and Hwang's stem cell research was duly approved by the government authority on 13 January. ${ }^{36}$ MBC aired a program "The Myth of Hwang Woo-suk and Suspicions over Eggs" in which the use of eggs from Hwang's researchers was revealed. ${ }^{36}$ When he learned the new information, Hwang admitted to these unethical activities, of paid eggs and use of his researchers as donors, on 24
November before a press conference upon which he declared that he resigned from any government or social organisations. ${ }^{40}$ To add fuel to the fire, Sun Jong Kim, co-author of both the 2004 and 2005 paper, revealed to MBC how the images were manipulated under the direction of Hwang. $^{25}$ Schatten asked Hwang to retract their 2005 paper on 13 December, and to Science to remove his name from paper on 14 December. Roh told the MBC on 15 December that Hwang had said to him earlier that "there are no cloned embryonic stem cells". ${ }^{41}$

The Seoul National University set up a ninemember disciplinary committee led by pharmacologist Myung Hee Chung on 11 December to investigate Hwang's lab. The report on 29 December 2005 confirmed the existence of data fabrication in Hwang's researches. ${ }^{42}$ Hwang openly accused the committee of prejudice and incompetence. ${ }^{25}$ The final report was made on 6 January 2006. DNA fingerprinting verified that the final cloned cell line did not match the donors' DNA and some cell lines were derived from IVF rather than from somatic cell nuclear transfer. ${ }^{37}$ Hwang was no longer able to form a barricade himself of dignity and conceded to the charges on fraud, but still claimed that he had a technique to do such cloning. On 10 January the university further announced that the 2004 cloning was also a fake. ${ }^{42}$ Upon the university's decision, Science retracted both the 2004 and 2005 papers on 20 January, with a concluding statement:

Because the final report of the SNU investigation indicated that a significant amount of the data presented in both papers is fabricated, the editors of Science feel that an immediate and unconditional retraction of both papers is needed. We therefore retract these two papers and advise the scientific community that the results reported in them are deemed to be invalid. ${ }^{43}$

Schatten was also investigated by the University of Pittsburgh on his involvement in the fraud from 5 December $2005 .{ }^{36}$ The university's report on 3 February 2006 acquitted him of research misconduct. The university panel also scrutinise his involvement in the Snuppy paper, which was found to be a genuine case of cloning, and came to the conclusion that his contribution did not warrant inclusion as an author. "We have no reason to doubt [his] statement to us that his major contribution ... was a suggestion that a professional photographer be engaged so that Snuppy would appear with greater visual appeal," the report mentioned. It was also revealed that Schatten received an exorbitant amount of consultation fee from Hwang - $\$ 40,000$ within a 15 -month period, which is way above the fee normally charged. As such the university adjudicated him of "research misbehaviour."

The Seoul National University declared on 20 March 2006 that "Hwang will be banned from 
working in a public position for 5 years after his dismissal and will receive only half of his retirement money." ${ }^{45}$ The case was filed under criminal offences with the first court hearing on 12 May 2006 on three charges: embezzling 2.8 billion won [US\$3 million]; committing fraud by knowingly using fabricated data to apply for research funds; and violating a bioethics law that prohibits the purchase of eggs for research. ${ }^{36}$ In a court ruling in October 2009, he was sentenced to a two-year suspended prison, ${ }^{46}$ and a three-year suspension from working. ${ }^{47} \mathrm{He}$ admitted before the court that he had directed fabrication (duplication) of images for the 2005 paper, that he gave research funds to certain Russian mafia figures for making a project to clone an extinct mammoth. ${ }^{48}$

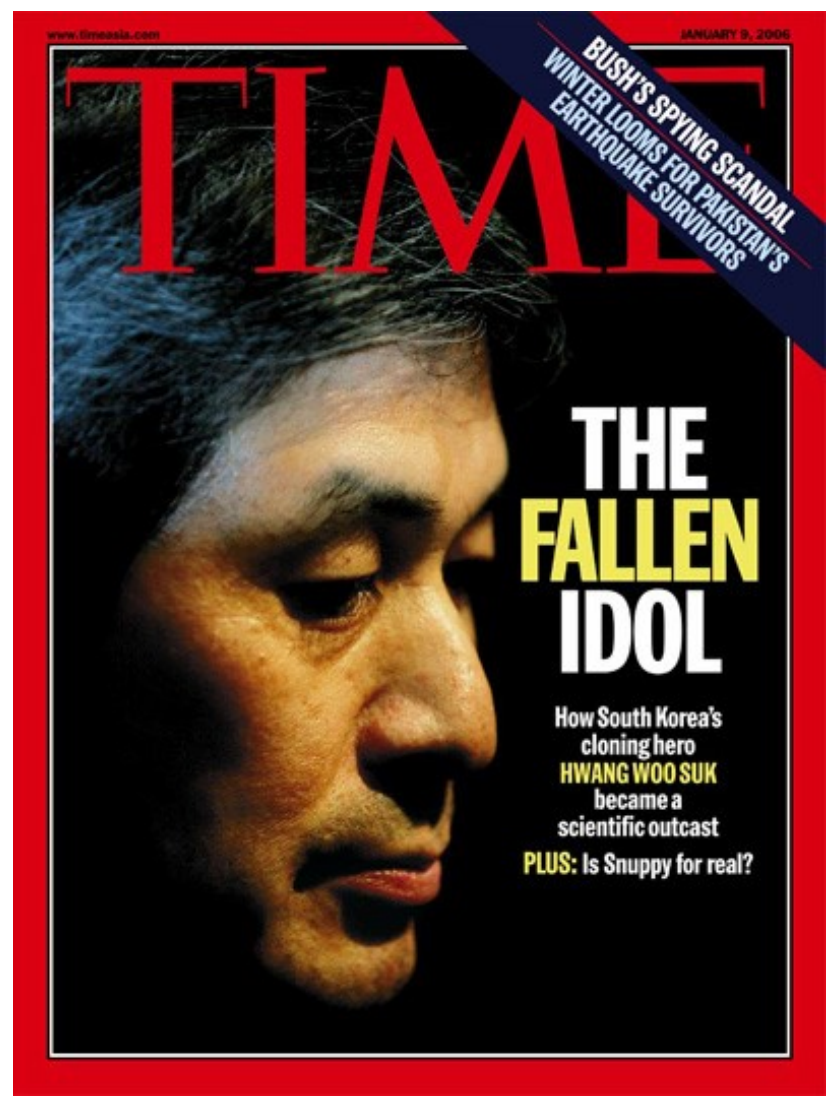

Figure 4 | The horribly humiliated Hwang.

South Korean law did not have criminal penalty on scientific fraud, and the court indicted Hwang on the grounds of buying human eggs which was a violation of the country's bioethics law and of embezzling 830 million won [US\$700,000] of government research fund. ${ }^{49}$ He filed for an appeal to the Supreme Court challenging his dismissal from the university. But the court's verdict in February 2014 stated rightly that he was guilty of embezzlement and bioethics violations, but acquitted him of fraud. ${ }^{46} \mathrm{He}$ is legally not a fraudster, though academically he is.

Hwang officially tendered his resignation from the university in December 2005, well before his banishment, and yet continued to publish several papers in the name of Seoul National University even after three years, ${ }^{37}$ and as of 2020 is still actively publishing from different affiliations. ${ }^{50,51}$

\section{Making New Humans in Our Images}

He Jiankui (Figure 5) is a Chinese biophysicist who while working at the Southern University of Science and Technology (SUSTech) in Shenzhen, China, created the first genetically edited babies in 2018. Employing a technique called CRISPR/Cas9 (for which Emmanuelle Charpentier of the Max Planck Institute for Infection Biology in Berlin and Jennifer A. Doudna of the University of California, Berkeley, won the 2020 Nobel Prize in Chemistry), he created babies purported to have resistance to HIV infection. The first babies were twins referred to by their pseudonyms Lulu and Nana, born in October 2018, and the second birth or the third baby born was in 2019. The People's Daily lauded the news as "a historical breakthrough in the application of gene editing technology for disease prevention." ${ }^{52}$ He was deservedly listed in Time magazine's "100 most influential people of 2019." But then his fame went down in shame. As Doudna herself wrote in the Time profile: "[He's] reckless experimentation on the girls in China not only shattered scientific, medical and ethical norms, it was also medically unnecessary... He's fateful decision to ignore the basic medical mantra of "do no harm" and risk the unintended consequences will likely be remembered as one of the most shocking misapplications of any scientific tool in our history." ${ }^{13}$ Reference to his name plummeted as a "rogue scientist", 54 "China's Dr Frankenstein", 55 and a "mad genius." 56

The debacle started on 10 June 2017, when He organised a conference at SUSTech campaigning his project to potential volunteers, HIV-positive couples, with an aim to create HIV-resistant babies. Participants were offered in vitro fertilisation along with gene-editing of their embryos so as to develop innate resistance to HIV infection in their offspring. In the audience were a couple, pseudonymously called Mark and Grace, ${ }^{57}$ an HIV-positive father and HIV-negative mother, who agreed to volunteer through informed consent. Six other couples having similar fertility problems subsequently enrolled. ${ }^{54}$ The couples were recruited through a Beijing-based AIDS support group called Baihualin China League. $B C L$ had received 200 willing participants and 50 of them were suggested to $\mathrm{He}^{58}$

The experiment was carried out in confidentiality. He Jiankui took sperms and eggs from the couples, performed IVF with the eggs and sperm, and then edited the genomes of the embryos using CRISPR/Cas9. The target of gene editing was CCR5, a gene that codes for a protein CCR5 that is required by HIV to enter cells. ${ }^{59}$ He was trying to reproduce 


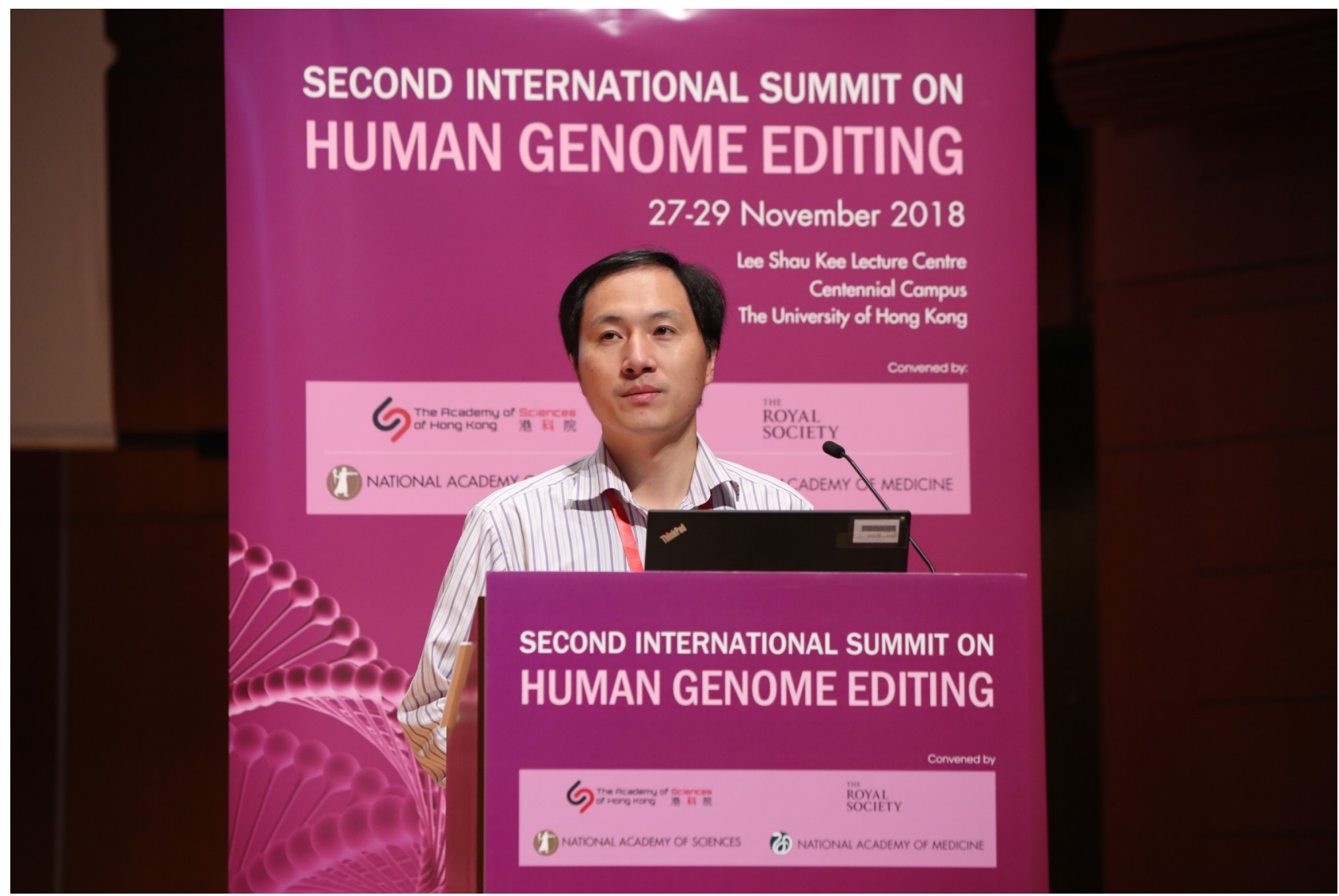

Figure 5 | He Jiankui presenting his creation of the first CRISPR-edited babies.

the phenotype of a specific mutation in the gene called CCR5- $\triangle 32$ (a mutant gene devoid of 32 base pairs of the normal gene) that few people naturally have and that possibly confers innate resistance to HIV, as seen in the case of the Berlin Patient. ${ }^{60}$ The first genome edited babies, Lulu and Nana were born in secrecy in October 2018. ${ }^{61}$ They were reported by He to be normal and healthy. ${ }^{62}$ The third baby was born around August 2019. ${ }^{63}$

He was planning to reveal his experiments and the birth of Lulu and Nana at the Second International Summit on Human Genome Editing, which was to be organized at the University of Hong Kong during 27-29 November 2018. ${ }^{64}$ However, on 25 November 2018, Antonio Regalado, senior editor for biomedicine of MIT Technology Review, posted on the journal's website about the experiment based on He Jiankui's applications for conducting clinical trial that had been posted earlier on the Chinese clinical trials registry. At the time, He refused to comment on the conditions of the pregnancy. ${ }^{65}$ Prompted by the premature publicity, $\mathrm{He}$ immediately posted about his experiment and the successful birth of the twins on YouTube in five videos the same day. ${ }^{66,67}$ The next day, the Associated Press made the first formal news, which was most likely a pre-written account before the publicity. ${ }^{68}$
Amidst the brewing furore, He was allowed to present his research at the Hong Kong meeting on 28 November under the title "CCR5 gene editing in mouse, monkey, and human embryos using CRISPRCas9". Robin Lovell-Badge, head of the Laboratory of Stem Cell Biology and Developmental Genetics at the Francis Crick Institute, who moderated the session recalled that $\mathrm{He}$ did not mention human embryos in the draft summary of the presentation. ${ }^{69}$ He had received an urgent message on 25 November through Doudna to whom He had confided the news earlier that morning. ${ }^{70}$ As the news already broke out before the presentation, $\mathrm{He}$ had to be brought in by the University of Hong Kong security from his hotel. During the discussion session, He asserted, "Do you see your friends or relatives who may have a disease? They need help," and continued, "For millions of families with inherited disease or infectious disease, if we have this technology we can help them. ${ }^{\prime \prime 1}$

He's presentation was immediately received with resentment and antipathy. Nobel laureate David Baltimore, chair of the organizing committee of the summit, was the first to react after He's speech, and declared his horror and dismay at He's work. ${ }^{69}$ There was widespread criticism in the media and scientific community over the conduct of the clinical project 
and its secrecy, ${ }^{72}$ and concerns raised for the long term well-being of Lulu and Nana. ${ }^{73,74}$ Bioethicist Henry T. Greely of Stanford Law School declared, "I unequivocally condemn the experiment, ${ }^{175}$ and later said, "He Jiankui's experiment was, amazingly, even worse than I first thought." ${ }^{176}$ The organising committee of the international summit issued a statement on 29 November 2018, remarking He's presentation:

We recommend an independent assessment to verify this claim and to ascertain whether the claimed DNA modifications have occurred. Even if the modifications are verified, the procedure was irresponsible and failed to conform with international norms. Its flaws include an inadequate medical indication, a poorly designed study protocol, a failure to meet ethical standards for protecting the welfare of research subjects, and a lack of transparency in the development, review, and conduct of the clinical procedures. ${ }^{77}$

What awaited $\mathrm{He}$ was no longer fame and fortune. A series of investigations was immediately opened by SUSTech, local authorities, and the Chinese government. On 29 November 2018, Chinese authorities suspended all of He's research activities, condemning that his work was "extremely abominable in nature" and a "violation of Chinese law" on the use of human gametes. ${ }^{78} \mathrm{He}$ was immediately detained in the university apartment. ${ }^{79}$

When later examined, the original consent forms were observed to be incomplete, misleading, and inadequate. ${ }^{57}$ The form titled "Informed Consent" contained dubious statements. The aim of the study was presented as "an AIDS vaccine development project" even though the study was not about vaccines. Many details were in technical jargon which would be incomprehensible to a layperson. ${ }^{80,81}$ One of the more peculiar statements is that if the participants decide to abort the experiment "in the first cycle of IVF until 28 days post-birth of the baby", they would have to "pay back all the costs that the project team has paid for you. If the payment is not received within 10 calendar days from the issuance of the notification of violation by the project team, another 100,000 RMB [renminbi, equivalent to over US\$150,000) of fine will be charged. ${ }^{\prime 82}$ This violates the very voluntary nature of the participation. ${ }^{80}$ When the place of the clinical experiment was investigated, SUSTech declared that the university was not involved and that $\mathrm{He}$ had been on unpaid leave since February 2018, and his department further attested that they were unaware of the research project. ${ }^{83}$

The Chinese law Measures on Administration of Assisted Human Reproduction Technology (2001) prohibits any genetic manipulation of human embryos for reproductive purposes while allowing assisted reproductive technology to be performed only by authorised personnel. ${ }^{84}$ On 7 March 2017, He Jiankui applied for ethics approval from Shenzhen HarMoniCare Women and Children's Hospital. In the application, He claimed that the genetically edited babies would be immune to HIV infection, in addition to smallpox and cholera, commenting: "This is going to be a great science and medicine achievement ever since the IVF technology which was awarded the Nobel Prize in 2010, and will also bring hope to numerous genetic disease patients." It was approved and signed by Lin Zhitong, the hospital administrator and one time Director of Direct Genomics, a company established by He. ${ }^{70}$ Upon an inquiry, the hospital denied such approval. The hospital's spokesperson declared that there were no records of such ethical documents, stating, "[The] gene editing process did not take place at our hospital. The babies were not born here either." ${ }^{85}$ It was later confirmed that the approval certificate was forged. ${ }^{86,87}$ Thus, He's study did not received ethical review and approval by an Institutional Ethics Board, as is required by the International Council for Harmonisation of Technical Requirements for Pharmaceuticals for Human Use. ${ }^{58}$

It is an established fact that C-C chemokine receptor type 5 (CCR5) is protein essential for HIV infection of the white blood cells by acting as coreceptor to HIV. Mutation in the gene CCR5 (called CCR5 32 because the mutation is specifically a deletion of 32 base pairs in human chromosome 3 ) renders HIV unable to bind, thus, provides resistance to HIV. ${ }^{88,89}$ Resistance is higher when mutations are in two copies (homozygous alleles) compared to only one copy (heterozygous alleles) in which the protection is very weak and slow. And not all homozygote individuals are completely resistant. ${ }^{90}$ In natural population, CCR5 32 homozygotes are rarer than heterozygotes. ${ }^{91}$ In 2007, Timothy Ray Brown (dubbed the Berlin patient) became the first person to be completely cured of HIV infection following a stem cell transplant from a CCR5 $\triangle 32$ homozygous donor. $^{92}$

He Jiankui overlooked these facts. However, rather than introducing the known CCR5- $\triangle 32$ mutation, He introduced a frameshift mutation intended to make the CCR5 protein entirely nonfunctional. According to He, Lulu and Nana carried both functional and mutant copies of CCR5 given mosaicism inherent in the present state of the art in germ-line editing. ${ }^{93}$ There are forms of HIV that use a different receptor instead of CCR5; therefore, the work of He did not theoretically protect Lulu and Nana from those forms of HIV. Two days after Lulu and Nana were born, their DNA were collected from blood samples of their umbilical cord and placenta. Whole genome sequencing confirmed the mutations. ${ }^{94}$ However, available sources indicate that Lulu and Nana are carrying incomplete CCR5 mutations. Lulu carries a mutant CCR5 that has a 15bp in-frame deletion only in one chromosome 3 (heterozygous allele) while the other chromosome 3 is normal; and Nana carries a homozygous mutant gene with a 4-bp deletion and a single base 
insertion. $^{95}$ He therefore failed to achieve the complete 32-bp deletion. ${ }^{96}$ Moreover, Lulu has only heterozygous modification which is not known to prevent HIV infection. ${ }^{89}$ Lulu and Nana's mutation alignment (in Sanger chromatogram) showed three modifications, while two should be expected. Particularly in Lulu, the mutation is much more complex that He's report. There were three different combinations of alleles: two normal copies of CCR5, one normal copy and one with a 15-bp deletion, and one normal copy and an unknown large insertion. $^{96}$ Because the babies' mutations are different from the typical CCR5 $\triangle 32$ mutation there is no evidence to claim that they would be HIV resistant. ${ }^{95}$

He had submitted two manuscripts to Nature and the Journal of the American Medical Association which were both rejected, mainly on ethical issues. ${ }^{97}$ An anonymous source tipped off the manuscripts to the MIT Technology Review, which publicised them on 3 December 2019. ${ }^{98,99} \mathrm{He}^{\prime}$ s first manuscript titled "Birth of Twins After Genome Editing for HIV Resistance" was submitted to Nature on 19 November. ${ }^{100}$ In an interview, William Hurlbut of Stanford University, once a confidant of He, opined that the condemnation of He's work would have been less harsh if the study had been published, and said, "If it had been published, the publishing process itself would have brought a level of credibility because of the normal scrutiny involved; the data analysis would have been vetted."101

Michael W. Deem, an American bioengineering professor at Rice University and He's doctoral advisor, was involved in the research, and was present when people involved in He's study gave consent. He was the only non-Chinese out of 10 authors listed in the manuscript submitted to Nature. Deem came under investigation by Rice University after news of the work was made public. ${ }^{102}$ The university's decision on Deem's involvement has never been disclosed, but had issued a statement that "this work as described in press reports violates scientific conduct guidelines and is inconsistent with ethical norms of the scientific community and Rice University." 103

On 30 December 2018, the Shenzhen Nanshan District People's Court sentenced He Jiankui to three years in prison and with a fine of 3 million RMB [US\$430,000]. Among the collaborators, only two were indicted - Zhang Renli of the Guangdong Academy of Medical Sciences and Guangdong General Hospital, received a two-year prison sentence and a 1-million RMB fine, and Qin Jinzhou of the Southern University of Science and Technology, received an 18-month prison sentence and a 500,000 RMB fine. ${ }^{104}$ The three were found guilty of having "forged ethical review documents and misled doctors into unknowingly implanting gene-edited embryos into two women." ${ }^{105}$

\section{Disclaimer}

Parallelism to related Wikipedia articles is warranted as they are by the same author, and published under CC-BY-SA license.

\section{Acknowledgement}

Journal access is courtesy of The Wikipedia Library of the Wikimedia Foundation.

\section{References}

1. Neema, P. K. (2018). Dishonesty in medical research and publication and the remedial measures. Annals of Cardiac Anaesthesia. 21 (2): 111113. doi: 10.4103/aca.ACA_58_18. PMC 5914207. PMID 29652268.

2. Tramèr, Martin R. (2013). The Fujii story: A chronicle of naive disbelief. European Journal of Anaesthesiology. 30 (5): 195-198. doi:10.1097/ EJA.0b013e328360a0db.

3. Fujii, Y.; Toyooka, H.; Ebata, T.; Amaha, K. (1993). Contractility of fatigued diaphragm is improved by dobutamine. Canadian Journal of Anaesthesia. 40 (5 Pt 1): 453-458. doi:10.1007/ BF03009517. PMID 8513526.

4. Fujii, Yoshitaka; Toyooka, Hidenori; Ebata, Toshiya; Amaha, Keisuke (2012). Retraction Note to: Contractility of fatigued diaphragm is improved by dobutamine. Canadian Journal of Anesthesia. 59 (12): 1181-1181. doi:10.1007/s12630012-9843-0.

5. Fujii, Y.; Saitoh, Y.; Tanaka, H.; Toyooka, H. (1999). Comparison of ramosetron and granisetron for preventing postoperative nausea and vomiting after gynecologic surgery. Anesthesia and Analgesia. 89 (2): 476-479. doi:10.1097/00000539199908000-00043. PMID 10439770.

6. Kranke, P.; Apfel, C. C.; Roewer, N. (2000). Reported data on granisetron and postoperative nausea and vomiting by Fujii et al. are incredibly nice! Anesthesia and Analgesia. 90 (4): 1004-1007. doi:10.1213/00000539-200004000-00053. PMID 10735823.

7. Fujii, Yoshitaka (2000). Reported data on granisetron and postoperative nausea and vomiting by Fujii et al. are incredibly nice! Anesthesia \& Analgesia. 90 (4): 1004. doi:10.1213/00000539-200004000-00054.

8. Marcus, Adam (7 March 2012). Japanese PONV researcher probed in sweeping research fraud case. Anesthesiology News. 
9. Shafer, Steven L. (2012). To our readers. Anesthesia $\mathcal{E}$ Analgesia.

10. Kuroda, Masaru (2012). Disciplinary decision concerning Dr. Yoshitaka Fujii. wwww.toho-u.ac.jp.

11. Adam, David (2019). How a data detective exposed suspicious medical trials. Nature. 571 (7766): 462-464. doi:10.1038/d41586-019-02241-z.

12. Carlisle, J. B. (2012). The analysis of 168 randomised controlled trials to test data integrity: Analysis of 168 randomised controlled trials to test data integrity. Anaesthesia. 67 (5): 521537. doi:10.1111/j.1365-2044.2012.07128.x.

13. Normile, Dennis (2012). A new record for retractions? (Part 2). Science. Online news.

14. Marcus, Adam (July 2, 2012). Report: Japanese anesthesiologist fabricated data in 172 studies; inquiry into PONV researcher Yoshitaka Fujii, MD, finds only three of 212 papers free of fraud. Anesthesiology News.

15. Normile, Dennis (2 July 2012). A new record for retractions? Science. Online news.

16. Kupferschmidt, Kai (2018). Tide of lies. Science. 361 (6403): 636-641. doi:10.1126/ science.361.6403.636.

17. Else, Holly (2019). What universities can learn from one of science's biggest frauds. Nature. 570 (7761): 287-288. doi:10.1038/ d41586-019-01884-2.

18. Bolland, Mark J.; Avenell, Alison; Gamble, Greg D.; Grey, Andrew (2016). Systematic review and statistical analysis of the integrity of 33 randomized controlled trials. Neurology. 87 (23): 2391-2402. doi:10.1212/WNL.0000000000003387.

19. Poole, Kenneth E.S.; Warburton, Elizabeth A.; Reeve, Jonathan (2005). Risedronate therapy for prevention of hip fracture after stroke in elderly women. Neurology. 65 (9): 1513-1514. doi:10.1212/ WNL.65.9.1513.

20. Halbekath, Jutta Martha; Schenk, Stefanie; von Maxen, Andreas; Meyer, Gabriele; Mühlhauser, Ingrid (2007). Risedronate for the prevention of hip fractures: concern about validity of trials. Archives of Internal Medicine. 167 (5): 513. doi:10.1001/archinte.167.5.513-b.

21. Sato, Yoshihiro (2007). Risedronate for the prevention of hip fractures: concern about validity of trials-Reply. Archives of Internal Medicine. 167 (5): $514 . \quad$ doi:10.1001/ archinte.167.5.514.

22. Gross, Robert A. (2016). Statistics and the detection of scientific misconduct. Neurology. 87 (23): 2388-
2388. doi:10.1212/WNL.0000000000003390.

23. Wanjek, Christopher (2017). Lies, mistakes \& more: These scientific papers got nixed in 2017. livescience.com

24. Scanlon, Charles (2006-01-13). Korea's national shock at scandal. BBC.

25. Cyranoski, David (2006). Who's who: A quick guide to the people behind the Woo Suk Hwang story. Nature. 060109-9. doi:10.1038/news060109-9.

26. Cyranoski, David (2003). Koreans rustle up madness-resistant cows. Nature. 426 (6968): 743743. doi:10.1038/426743a

27. Hwang, Woo Suk; Ryu, Young June; Park, Jong Hyuk; Park, Eul Soon; Lee, Eu Gene; Koo, Ja Min; Jeon, Hyun Yong; Lee, Byeong Chun; Kang, Sung Keun; Kim, Sun Jong; Ahn, Curie (2004). Evidence of a pluripotent human embryonic stem cell line derived from a cloned blastocyst. Science. 303 (5664): 1669-1674. doi:10.1126/science.1094515. PMID 14963337.

28. Kluger, Jeffrey (2004). The 2004 TIME 100 TIME. Time.

29. Lee, Byeong Chun; Kim, Min Kyu; Jang, Goo; Oh, Hyun Ju; Yuda, Fibrianto; Kim, Hye Jin; Shamim, M. Hossein; Kim, Jung Ju; Kang, Sung Keun; Schatten, Gerald; Hwang, Woo Suk (2005). Dogs cloned from adult somatic cells. Nature. 436 (7051): 641-641. doi:10.1038/436641a.

30. Associated Press (3 August 2005). Koreans produce world's first cloned dog. NBC News.

31. Vogel, Gretchen (2005). First dog cloned. Science. Online news.

32. TIME cover: The Most Amazing Inventions of 2005. Time. 2005.

33. Cyranoski, David (2004). Korea's stem-cell stars dogged by suspicion of ethical breach. $\quad$ Nature. $429 \quad$ (6987): 3-3. doi:10.1038/429003a. ISSN 0028-0836.

34. Hwang, Woo Suk; Roh, Sung Il; Lee, Byeong Chun; Kang, Sung Keun; Kwon, Dae Kee; Kim, Sue; Kim, Sun Jong; Park, Sun Woo; Kwon, Hee Sun; Lee, Chang Kyu; Lee, Jung Bok (2005). Patient -specific embryonic stem cells derived from human SCNT blastocysts. Science. 308 (5729): 17771783. doi:10.1126/science.1112286. PMID 15905366.

35. Vogel, G. (2005). Collaborators split over ethics allegations. Science. 310 (5751): 1100-1100. doi:10.1126/science.310.5751.1100.

36. Timeline of a controversy. Nature: 051219-3. 2005. doi:10.1038/news051219-3.

37. van der Heyden, M. a. G.; van de Ven, T.; Opthof, 
T. (2009). Fraud and misconduct in science: the stem cell seduction: Implications for the peerreview process. Netherlands Heart Journal. 17 (1): 25 -29. doi:10.1007/BF03086211. PMC 2626656. PMID 19148335.

38. Resnik, David B.; Shamoo, Adil E.; Krimsky, Sheldon (2006). Fraudulent human embryonic stem cell research in South Korea: lessons learned. Accountability in Research. 13 (1): 101-109. doi:10.1080/08989620600634193. PMC 1892198. PM ID 16770863.

39. Holden, C. (2005). Korean cloner admits lying about oocyte donations. Science. 310 (5753): 14021403. doi:10.1126/science.310.5753.1402. ISSN 00368075 .

40. Cyranoski, David (2005). Stem-cell pioneer resigns. Nature: 051121-12. doi:10.1038/ news051121-12.

41. Cyranoski, David (2005). Stem-cell pioneer accused of faking data. Nature: 051212 14. doi:10.1038/news051212-14.

42. Normile, D. (2009). Hwang convicted but dodges jail; stem cell research has moved on. Science. 326 (5953): 650-651. doi:10.1126/ science.326_650a.

43. Kennedy, Donald (2006). Editorial retraction. Science. 311 (5759): 335.2-335. doi:10.1126/science.1124926.

44. Holden, C. (2006). Korean stem cell scandal: Schatten: Pitt panel finds 'misbehavior' but not misconduct. Science. 311 (5763): 928-928. doi:10.1126/science.311.5763.928.

45. Wohn, Y. (2006). Seoul National University dismisses Hwang. Science. 311 (5768): 1695b1695b. doi:10.1126/science.311.5768.1695b.

46. Ahn, Mi-Young; Normile, Dennis (2014). Korean Supreme Court upholds disgraced cloner's criminal sentence. Science. Online news.

47. Vogel, Gretchen (2010). South Korean Court reduces Hwang's sentence. Science. Online news.

48. Hwang admits faking data. Science. 2006. Online news.

49. Cyranoski, David (2009). Woo Suk Hwang convicted, but not of fraud. Nature. 461 (7268): 1181-1181. doi:10.1038/4611181a.

50. Cai, Lian; Jeong, Yeon-woo; Jin, Yong-xun; Lee, Jong-yun; Jeong, Yeon-ik; Hwang, Kyu-chan; Hyun, Sang-hwan; Hwang, Woo-suk (2020). Effects of human recombinant granulocyte-colony stimulating factor treatment during in vitro culture on porcine pre-implantation embryos. Plos
One. 15 (3): e0230247. doi:10.1371/ journal.pone.0230247. PMC 7077850. PMID 32182268 .

51. Eun, Kiyoung; Hong, Nayoung; Jeong, Yeon Woo; Park, Min Gi; Hwang, Seon-Ung; Jeong, Yeon I. K.; Choi, Eun Ji; Olsson, P. Olof; Hwang, Woo Suk; Hyun, Sang-Hwan; Kim, Hyunggee (2020). Transcriptional activities of human elongation factor- $1 \alpha$ and cytomegalovirus promoter in transgenic dogs generated by somatic cell nuclear transfer. Plos One. 15 (6): e0233784. doi:10.1371/ journal.pone.0233784. PMC 7269240. PMID 324920 24.

52. Li, Jing-ru; Walker, Simon; Nie, Jing-bao; Zhang, Xin-qing (2019). Experiments that led to the first gene-edited babies: the ethical failings and the urgent need for better governance. Journal of Zhejiang University Science B. 20(1): 32-38. doi: 10.1631/zus.B1800624. PMC 6331330. PMID 30614228.

53. Doudna, Jennifer (18 April 2019). 100 Most Influential People - He Jiankui. Time. Online.

54. Cohen, Jon (2 August 2019). Inside the circle of trust. Science. 365 (6452): 430-437. doi:10.1126/ science.365.6452.430. PMID 31371593.

55. Yan, Sophia (28 November 2018). China's 'Dr Frankenstein' says second woman in early pregnancy with gene-edited babies. The Telegraph.

56. Low, Zoe (27 November 2018). China's gene editing Frankenstein had dreams of being Chinese Einstein. South China Morning Post.

57. Caplan, Arthur (2019). Getting serious about the challenge of regulating germline gene therapy. Plos Biology. 17 (4): e3000223. doi:10.1371/ journal.pbio.3000223. PMC 6490874. PMID 310391 43.

58. Jonlin, Erica C. (2020). Informed consent for human embryo genome editing. Stem Cell Reports. 14 (4): 530-537. doi:10.1016/ j.stemcr.2020.03.010. PMC 7160388. PMID 32294411.

59. de Silva E, Stumpf MP (Dec 2004). HIV and the CCR5-Delta32 resistance allele. FEMS Microbiology Letters. $241 \quad$ (1): 1-12. doi:10.1016/ j.femsle.2004.09.040. PMID 15556703.

60. Allers, K.; Hutter, G.; Hofmann, J.; Loddenkemper, C.; Rieger, K.; Thiel, E.; Schneider, T. (2010). Evidence for the cure of HIV infection by $\begin{array}{llll}\text { CCR5 32/ } 32 & 32 \text { stem cell }\end{array}$ transplantation. Blood. 117 (10): 2791-2799. doi:10.1182/blood-2010-09-309591. PMID 21148083.

61. Bulluck, Pam (14 April 2019). Gene-edited babies: 
What a Chinese scientist told an American mentor. The New York Times. Online.

62. Begley, Sharon (28 November 2018). Amid uproar, Chinese scientist defends creating gene-edited babies - STAT. STAT News.

63. Cyranoski, David (2019). The CRISPR-baby scandal: what's next for human geneediting. Nature. 566 (7745): 440-442. doi:10.1038/ d41586-019-00673-1. PMID 30809070.

64. Galvin, Molly (26 November 2018). Statement from the Organizing Committee on Reported Human Embryo Genome Editing. www8.nationalacademies.org.

65. Regalado, Antonio (25 November 2018). Chinese scientists are creating CRISPR babies. MIT Technology Review.

66. The He Lab (25 November 2018). About Lulu and Nana: Twin Girls Born Healthy After Gene Surgery As Single-Cell Embryos. YouTube.com.

67. Dyer, Owen (2018). Researcher who edited babies' genome retreats from view as criticism mounts. BMJ. 363: k5113. doi:10.1136/bmj.k5113. PMID 30504437.

68. Greely, Henry T (2019). CRISPR'd babies: human germline genome editing in the 'He Jiankui affair'. Journal of Law and the Biosciences. 6 (1): 111183. doi:10.1093/jlb/lsz010. PMC 6813942. PMID 31666967.

69. Lovell-Badge, Robin (2019). CRISPR babies: a view from the centre of the storm. Development. 146 (3): dev175778. doi:10.1242/dev.175778. PMID 30728161 .

70. Cohen, Jon (2 August 2019). Inside the circle of trust. Science. 365 (6452): 430-437. doi:10.1126/ science.365.6452.430. PMID 31371593.

71. Cyranoski, David (2018). CRISPR-baby scientist fails to satisfy critics. Nature. 564 (7734): 13-14. doi:10.1038/d41586-018-07573-w. PMID 30514937.

72. Kolata, Gina; Belluck, Pam (5 December 2018). Why are scientists so upset about the first Crispr babies? - Only because a rogue researcher defied myriad scientific and ethical norms and guidelines. We break it down. The New York Times.

73. Begley, Sharon (28 November 2018). Amid uproar, Chinese scientist defends creating gene-edited babies - STAT. STAT News.

74. Cyranoski, David (27 November 2018). How the genome-edited babies revelation will affect research - Some scientists worry the startling claim will lead to knee-jerk regulations and damage the public's trust in gene editing. Nature. doi:10.1038/ d41586-018-07559-8.

75. Farr, Cristina (26 November 2018). Experiments to gene-edit babies are 'criminally reckless,' says Stanford bio-ethicist. CNBC.

76. Greely, Henry T. (15 April 2019). He Jiankui, embryo editing, CCR5, the London patient, and jumping to conclusions. STAT NEWS.

77. The National Academies of Sciences, Engineering, and Medicine (2018). Statement by the Organizing Committee of the Second International Summit on Human Genome Editing. www8.nationalacademies.org.

78. Jiang, Steven; Regan, Helen; Berlinger, Joshua (29 November 2018). China suspends scientists who claim to have produced first gene-edited babies. CNN News.

79. Chen, Elsi; Mozur, Paul (28 December 2018). Chinese scientist who claimed to make genetically edited babies is kept under guard. The New York Times.

80. Li, Jing-ru; Walker, Simon; Nie, Jing-bao; Zhang, Xin-qing (2019). Experiments that led to the first gene-edited babies: the ethical failings and the urgent need for better governance. Journal of Zhejiang University Science B. 20(1): 32-38. doi:10.1631/jzus.B1800624. PMC 6331330. PMID 30614228

81. Caplan, Arthur (2019). Getting serious about the challenge of regulating germline gene therapy. Plos Biology. 17 (4): e3000223. doi:10.1371/ journal.pbio.3000223. PMC 6490874. PMID 310391 43.

82. Shaw, David (3 January 2020). The consent form in the Chinese CRISPR study: In search of ethical gene editing. Journal of Bioethical Inquiry. 17 (Online): 5-10. doi:10.1007/s11673-019-09953-x. PMC 7223878. PMID 31900853.

83. Cyranoski, David; Ledford, Heidi (26 November 2018). Genome-edited baby claim provokes international outcry. Nature. 563 (7733): 607-608. doi:10.1038/d41586-018-07545-0. PMID 30482929.

84. Zhang, Laney (2018). On gene edited babies: What Chinese law says. In Custodia Legis: Law Librarians of Congress.

85. Liao, Rita (26 November 2018). Hospital in China denies links to world's first gene-edited babies. Techcrunch.

86. Former ethics committee member of Shenzhen Hemei Women's and Pediatric Hospital: the signature of the examination application may be forged Chinese. wxn.qq.com. 
87. Cyranoski, David (6 March 2019). China to tighten rules on gene editing in humans. Nature. doi:10.1038/d41586-019-00773-y.

88. Barmania, Fatima; Pepper, Michael S. (2013). C-C chemokine receptor type five (CCR5): An emerging target for the control of HIV infection. Applied \& Translational Genomics. 2 (1): 316. doi:10.1016/j.atg.2013.05.004. PMC 5133339. PMID 27942440.

89. Rautenbach, Anandi; Williams, Aurelia A. (2020). Metabolomics as an approach to characterise the contrasting roles of CCR5 in the presence and absence of disease. International Journal of Molecular Sciences. 21 (4): 1472. doi:10.3390/ijms21041472. PMC 7073144. PMID 32098198.

90. Smoleń-Dzirba, J; Rosińska, M; Janiec, J; Beniowski, M; Cycoń, M; Bratosiewicz-Wąsik, J; Wąsik, TJ (2017). HIV-1 infection in persons homozygous for CCR5- $\triangle 32$ allele: The next case and the review. AIDS Reviews. 19 (4): 219230. PMID 28534889.

91. Trecarichi, Enrico M; Tumbarello, Mario; Donati, Katleen; Tamburrini, Enrica; Cauda, Roberto; Brahe, Christina; Tiziano, Francesco D (2006). Partial protective effect of CCR5-Delta 32 heterozygosity in a cohort of heterosexual Italian HIV-1 exposed uninfected individuals. AIDS Research and Therapy. 3 (1): 22. doi:10.1186/17426405-3-22. PMC 1592103. PMID 16999868.

92. Lederman, Michael M.; Pike, Earl (2017). Ten years HIV free: An interview with The Berlin Patient, Timothy Ray Brown. Pathogens and Immunity. 2 (3): 422-430. doi:10.20411/pai.v2i3.226. PMC 5708572. PMID 29202113.

93. Cohen, Jon (2019). Did CRISPR help-or harmthe first-ever gene-edited babies? Science. doi:10.1126/science.aay9569.

94. Wang, Haoyi; Yang, Hui (2019). Gene-edited babies: What went wrong and what could go wrong. Plos Biology. 17 (4): e3000224. doi:10.1371/ journal.pbio.3000224. PMC 6490877. PMID 310391 44.

95. Ryder, Sean P. (2018). \#CRISPRbabies: Notes on a Scandal. The CRISPR Journal. 1 (6): 355-357. doi:10.1089/crispr.2018.29039.spr. PMC 6345105. PMID 30687814.
96. Rothschild, Jodie (2020). Ethical considerations of gene editing and genetic selection. Journal of General and Family Medicine. 21 (3): 37-47. doi:10.1002/jgf2.321. PMC 7260159. PMID 32489755.

97. Magowan, Jakki (9 December 2019). Unpublished paper surfaces about the Chinese genome-edited babies - BioNews. www.bionews.org.uk.

98. Regalado, Antonio (3 December 2019). China's CRISPR babies: Read exclusive excerpts from the unseen original research - He Jiankui's manuscript shows how he ignored ethical and scientific norms in creating the gene-edited twins Lulu and Nana. MIT Technology Review.

99. Musunuru, Kiran (3 December 2019). Opinion: We need to know what happened to CRISPR twins Lulu and Nana - The unpublished research paper by He Jiankui about the creation of the babies shows proof of attempted gene editing gone awry. MIT Technology Review.

100. Regalado, Antonio (3 December 2019). Why the paper on the CRISPR babies stayed secret for so long. MIT Technology Review.

101. Cloer, Dan (2019). Interview: genetically modified babies: an insider's view. www.vision.org.

102. LaMotte, Sandee (27 November 2018). Rice professor under investigation for role in 'world's first gene-edited babies'. CNN News.

103. Holmes, Riley (2020). Rice Ph.D graduate known as 'CRISPR Baby' scientist sentenced to three years in prison. The Rice Thresher.

104. Cyranoski, David (3 January 2020). What CRISPRbaby prison sentences mean for research - Chinese court sends strong signal by punishing He Jiankui and two colleagues. Nature. 577 (7788): 154155. doi:10.1038/d41586-020-00001-y. PMID 31911693.

105. Normile, Dennis (30 December 2019). Chinese scientist who produced genetically altered babies sentenced to 3 years in jail. Science. doi:10.1126/ science.aba7347. 